\title{
PERSONAL GROWTH INITIATIVE AND SUBJECTIVE WELL-BEING: THE MEDIATION ROLE OF MEANING IN LIFE
}

\section{INICIATIVA DE CRECIMIENTO PERSONAL Y BIENESTAR SUBJETIVO: EL ROL MEDIADOR DEL SIGNIFICADO EN LA VIDA}

\author{
Clarissa Pinto PiZArro Freitas ${ }^{1}$, Elif MERVE CANKAYA ${ }^{2}$, \\ BRUNO FIGUEIREDO DAMÁSIO ${ }^{3}$, EMILY JEAN HADDAD ${ }^{4}$, \\ HELDER HIROKI KAMEI ${ }^{5}$, PATRICIA RENOVATO TOBO ${ }^{5}$, AND \\ SílVIA HELENA KOLLER ${ }^{4}$
}

Cómo referenciar este artículo/How to reference this article:

Freitas, C. P. P., Cankaya, E. M., Damásio, B. F., Haddad, E. J., Kamei, H. H., Tobo, P. R., \& Koller, S. H. (2018). Personal Growth Initiative and Subjective Well-being: The Mediation Role of Meaning in Life [Iniciativa de crecimiento personal y bienestar subjetivo: el rol mediador del significado en la vida]. Acción Psicológica, 15(2), 39-50. https://doi.org/10.5944/ap.15.2.22002

\begin{abstract}
This study investigated the mediating effect of meaning in life on the relationship between personal growth initiative
\end{abstract}

and subjective well-being. The sample was composed of a total of 1,899 Brazilian participants who voluntarily took part in this study by completing the study survey. Based on the results of the structural equation modeling, the relationship between personal growth initiative and

Correspondence address: Clarissa Pinto Pizarro Freitas. Salgado de Oliveira University, Brasil.

Email: freitas.cpp@gmail.com

ORCID: Clarissa Pinto Pizarro Freitas (http://orcid.org/0000-0002-2274-8728), Elif Merve Cankaya (http://orcid.org/0000-0001-9626-6775), Bruno Figueiredo Damásio (http://orcid.org/0000-0002-1150-092X), Emily Jean Haddad (http://orcid.org/0000-0002-8132-7413), Helder Hiroki Kamei (http://orcid.org/0000-0003-4672-9940), Patricia Renovato Tobo (http://orcid.org/0000-0002-8798-0747) y Sílvia Helena Koller (http://orcid.org/0000-0001-9109-6674).

${ }^{1}$ Salgado de Oliveira University, Brasil.

${ }^{2}$ Ohio State University, USA.

${ }^{3}$ Federal University of Rio de Janeiro (UFRJ), Brasil.

${ }^{4}$ Federal University of Rio Grande do Sul (UFRGS), Brasil.

${ }^{5}$ Advanced Research in Sciences of Well-being, Brasil.

Retrieved: May 3, 2018.

Aceptado: October 26, 2018. 
subjective well-being was found to be partially mediated by the presence of meaning in life. Age was found to influence the mediation, as older participants reported greater personal growth initiative and meaning in their lives. Limitations of the study, as well as directions for future research are discussed.

Keywords: Personal growth initiative; Meaning in life; Subjective well-being.

\section{Introduction}

Positive psychology is the scientific study of the mechanisms that facilitate the optimal functioning of people, institutions, and societies for improving quality of life (Gable \& Haidt, 2005; Seligman \& Csikszentmihalyi, 2000). Positive psychology emerged as a reaction to the overwhelming emphasis given in the field of psychology to examining the negative aspects of human functioning and human pathology (Gable \& Haidt, 2005). Positive psychology encourages psychologists and researchers to adopt a more balanced understanding of human experiences and functioning, and reminds them not only to explore human pathology and ill-functioning, but also to examine human strengths, virtues, and well-being (Seligman \& Csikszentmihalyi, 2000). One of the core positive psychology concepts that has started to receive greater scientific attention from scholars is subjective well-being (SWB; Diener, Suh, Lucas, \& Smith, 1999).

A growing body of research has been conducted on SWB over the last decades, thanks to advances in the field of positive psychology. SWB is defined as one's cognitive and affective evaluations of one's quality of life (Diener, Suh, Oishi, 1997). The construct consists of three components: (1) an individual's level of life satisfaction, and the presence of (2) positive mood and (3) negative mood (Diener et al., 1999). While life satisfaction constitutes the cognitive aspect of SWB, positive and negative moods constitute SWB's affective domain. Diener et al. (1999) describe individuals with high levels of SWB as those who possess greater levels of life satisfaction (e.g., positive judgments about their life), positive affect (e.g., gratitude, hope) and low levels of negative affect (e.g., anger, sadness).

This study sought to extend the research on SWB by exploring the role of two psychological constructs -personal growth initiative (PGI) and meaning in life (MIL)in promoting SWB.

\section{The Relation Between PGI and SWB}

An essential indicator of healthy personality is continued personal development and growth throughout one's lifespan (Robitschek, 1998). PGI is a construct composed of distinct cognitive and behavioral dimensions; it is defined as the ability to intentionally change personal beliefs and behaviors to grow as a person (Robitschek, 1998; Robitschek et al., 2012). The PGI construct includes four components: readiness for change, planfulness, using resources, and intentional behavior. While readiness for change (identifying opportunities for personal growth) and planfulness (planning strategies for self-improvement) characterize the cognitive mindset of PGI, the dimensions of using resources (searching for support to achieve personal growth) and intentional behavior (developing actions for self-improvement) capture the behavioral aspect of the construct (Robitschek et al., 2012).

The core characteristic of PGI is intentionality and active engagement in the process of self-improvement (Robitschek, 1998). The intentional growth process reinforces engagement in behaviors that aim to fulfill one's potential and optimize functioning in life. Highly intentional efforts to grow and develop are also seen to promote various aspects of well-being, including SWB (Robitschek \& Keyes, 2009). Consistent with PGI theory, the findings of prior research support PGI as a predictor of several well-being structures (e.g., emotional, social, and psychological) (Robitschek \& Keyes, 2009; Robitschek \& Kashubeck, 1999) and revealing positive associations between PGI and components of SWB (e.g., life satisfaction, positive mood) (Robitschek \& Keyes, 2009). Low levels of PGI, on the other hand, have been related to lower levels of anxiety, depression, and emotional distress (Robitschek \& Kashubeck, 1999).

\section{MIL and its relation to SWB and PGI}


The literature contains differing conceptualizations of MIL, as well as perspectives on how to achieve life meaning (Steger, Frazier, Oishi, \& Kaler, 2006). Despite these variations, the feeling that one's life is meaningful has been accepted as an essential determinant of optimal human functioning (Steger et al., 2006). Recently, a conceptual model of MIL that incorporates both the cognitive and motivational dimensions of the construct was proposed, and MIL was defined as "the sense made of, and significance felt regarding, the nature of one's being and existence" (Steger et al., 2006, p. 81).

MIL has been viewed as an important indicator of greater well-being (Cohen \& Cairns, 2012; Steger, Shin, Shim, \& Fitch-Martin, 2013). The findings of prior research show a positive association between higher levels of MIL and a wide range of well-being indicators (Cohen \& Cairns, 2012; Kashdan \& Steger, 2007; Steger, Oishi, \& Kashdan, 2009; Steger, Oishi, \& Kesebir, 2011; Steger et al., 2006; Yalçın \& Malkoç, 2015). Furthermore, finding life meaningless has been associated with illbeing, negative emotions and depression (Park, Park, \& Peterson, 2010; Steger et al., 2006).

MIL has two components: presence of meaning and search for meaning. While the presence-of-meaning dimension measures cognitive appraisals that one's life is meaningful, search for meaning assesses one's general tendency to seek meaning in life (Steger et al., 2006). These two dimensions of MIL are independent and distinct from each other (Steger et al., 2006). More specifically, presence of meaning was found to be positively related to well-being and positive emotions, whereas search for meaning was positively associated with negative affect and a lower level of well-being (Steger et al., 2006).

Presence of MIL is interpreted as construct with positive life and psychological outcomes, since it has been found to positively associated to personal resources, such as self-esteem (Steger et al., 2006), hope and forgiveness (Yalçın \& Malkoç, 2015), and several well-being indicators and components, like happiness (Cohen \& Cairns, 2012; Steger et al., 2009), life satisfaction (Kashdan \& Steger, 2007; Steger et al., 2006, 2009; Steger et al., 2011), positive affect (Steger et al., 2006, 2009, 2011; Yalçın \&
Malkoç, 2015) and subjective well-being (Doğan, Sapmaz, Tel, Sapmaz, \& Temizel. 2012). Also, presence of MIL is negatively associated with depression (Park et al., 2010) and negative affect (Park et al., 2010; Steger et al., 2006, 2009, 2011; Yalçın \& Malkoç, 2015).

On the other hand, high levels of search for MIL are associated to lower levels of personal resources and wellbeing indicators (Kashdan \& Steger, 2007; Steger et al., 2006, 2009, 2011; Yalçın \& Malkoç, 2015). Search for MIL had shown negative relations with forgiveness (Yalçın \& Malkoç, 2015), love, joy, self-esteem (Steger et al., 2006), happiness (Cohen \& Cairns, 2012; Steger et al., 2009), life satisfaction (Kashdan \& Steger, 2007; Steger et al., 2006, 2009, 2011; Yalçın \& Malkoç, 2015), positive affect (Steger et al., 2006, 2009, 2011; Yalçın \& Malkoç, 2015) and subjective well-being (Doğan et al, 2012). Moreover, positive associations were found between search for MIL and depression, neuroticism, and negative affect (Steger et al., 2006).

Given the fact that presence of MIL is linked to desirable life and psychological outcomes and search for MIL is often reported to associated with undesirable outcomes (Steger et al., 2009), presence of MIL is viewed as an indicator of adaptive adaptive functioning and has been utilized when examining MIL in relation to positive psychological constructs (i.e., Battersby \& Phillips, 2016; Yalçin \& Malkoç, 2015).

MIL is also included as an essential concept in the growth literature (Taubman-Ben-Ari, Ben Shlomo, \& Findler, 2012). This is because the growth process involves changes in the meaning one attaches to one's life (Taubman-Ben-Ari \& Wientroub, 2008). Moreover, in an earlier Australian study, personal growth was reported to be an important source of MIL across lifespan (Prager, 1996). Very recently, personal growth has been identified as an important source of MIL in two qualitative inquiries conducted with samples of undergraduate and graduate students (Hill et al., 2013, 2015). Empirical research lends support to the theoretical assumption of a relationship between MIL and personal growth by revealing a strong positive association between them (e.g., Ivtzan, Chan, Gardner, \& Prashar, 2013; Kashdan \& Steger, 2007). Specifically, presence of MIL is positively associated with 
PGI (Ivtzan et al., 2013) and growth behavior (Kashdan \& Steger, 2007).

\section{The Current Study}

Despite the theoretical and preliminary empirical relations among PGI, MIL, and SWB, and their relevance to optimal functioning, no studies were found that examine the underlying mechanism among them simultaneously. In light of the proposed theoretical relations among PGI, presence of MIL, and SWB elaborated in the preceding paragraphs, a meditational model was hypothesized to describe their inter-relationships.

Given the independent variable of this study, SWB, and the fact that the two distinct components of MIL, presence of MIL and search for MIL, found to have opposite patterns of correlations with well-being in previous research studies, only the presence of MIL was examined as an indicator of life meaning in this study. More specifically, we hypothesized PGI as a predictor of SWB, and explored whether presence of MIL serves as a mediator on the relation between PGI and SWB. We expected to find that greater levels of PGI promote greater degree of presence of MIL, both of which, in turn, can predict greater levels of SWB.

\section{Method}

\section{Participants}

The participants consisted of 1,899 Brazilians whose age ranged from 18 to 88 years $(M=38.7, S D=16.1)$. The majority of participants were female $(64 \%)$, with a mean age of $38.6(S D=16.1)$. Based on the Brazilian Institute of Geography and Statistics (IBGE) guidelines (IBGE, 1999), 756 of participants (40\%) were classified as young adults, 838 of participants (44\%) were mid-adults, and 305 of participants $(16 \%)$ were elders. With respect to the marital status of participants, $46 \%$ of the sample was single, $30 \%$ was married, $8 \%$ was divorced, $11 \%$ was in a stable relationship, and the remaining $3 \%$ of the sample was widowed.
Participants were reached through various recruitment methods, including personal and media invitations, outreach by a research recruitment company, and recruitment within social and occupational institutions. While $62 \%$ of the completed questionnaires were gathered through a web-based platform, the remaining $38 \%$ of completed survey responses were collected in paper-and-pencil form.

\section{Instruments}

Sociodemographic questionnaire. This questionnaire was used to assess socio-demographic characteristics of the sample.

Personal Growth Initiative Scale - II (PGIS-II, Robitschek et al., 2012, Brazilian version adapted by Freitas, Damásio, Kamei, Tobo, Koller, \& Robitschek, 2018). The PGIS-II aims to evaluate the intentional growth and change process. The instrument is a 16-item Likert-type scale item (ranging from 0 -Disagree strongly to 5-Agree strongly). In this sample, the coefficient alpha of the total scale was $\alpha=.91$, and PGI dimensions were as following: Planfulness, $\alpha=.86$, Readiness for Change, $\alpha=.78$, Intentional Behavior, $\alpha=.77$, and Using Resources, $\alpha=.75$. The goodness-of-fit indexes of the instrument for the higher-order four-factor solution were considered acceptable, suggesting the adequacy of the scale: $\mathrm{CFI}=.95$, $\mathrm{TLI}=.93, \mathrm{RMSEA}=.10(90 \%$ I.C. $=.09-.10)$.

Meaning in Life Questionnaire (MLQ, Steger et al., 2006; Brazilian version adapted by Damásio \& Koller, 2015). The MLQ is a 10-item scale that evaluates search for MIL, the intentional effort of individuals to find meaning in their lives, and presence of MIL, the cognitive appraisals of individuals whether life is meaningful. Each subscale (SMLQ and PMLQ) has five items and can be assessed separately from each other, which provides greater convenience for theoretical and empirical utilization of the measurement (Steger et al., 2006). Participants rated their agreement with each item on a 7-point Likerttype scale (ranging from 1 -absolutely untrue to 7-absolutely true). In the current study, the MLQ presented satisfactory value of coefficient alpha for the subscale search for MIL $(\alpha=.89)$ and presence of MIL $(\alpha=.88)$ 
and goodness-of-fit indexes $(\mathrm{CFI}=.95$, TLI $=.94$, RMSEA $=.15(90 \%$ C.I. $=.15-.16)$.

Subjective Well-being. A composite score of SWB (CSWB) was calculated through a higher-order factor that results from the combination of life satisfaction, positive and negative affect (Busseri \& Sadava, 2011; Linley, Maltby, Wood, Osborne, \& Hurling, 2009). Life satisfaction was assessed through Satisfaction with Life Scale (SWLS, Diener, Emmons, Larsen, \& Griffin, 1985, Brazilian version adapted by Gouveia, Milfont, Fonseca, \& Coelho, 2009). The SWLS is a 5-items scale evaluates the general positive cognitive appraisals with satisfaction in life. The positive and negative affect were assessed through Positive and Negative Affect Schedule (PANAS, Watson, Clark, \& Tellegen, 1988; Brazilian version adapted by Galinha \& Pais-Ribeiro, 2005). The PANAS is a two-factor scale, composed of 20 items. While 10 items of the instrument evaluate the general tendency of feeling positive emotions PANAS-PA, the remaining 10 items assess the general tendency to feel negative emotions PANAS-NA. In the sample of this study, the higher-order three-factor solution showed satisfactory goodness-of-fit indexes $(\mathrm{CFI}=.95, \quad \mathrm{TLI}=.95, \quad \mathrm{RMSEA}=.06 \quad(90 \%$ I.C. $=.05-.06))$.

\section{Data analysis}

Descriptive statistics were calculated using the raw scores of the participants in each scale. To calculate the raw scores of all variables, the items of each construct were summed and divided by the number of items of each scale. To calculate CSWB raw score, the NA items were inverted. After this procedure, the items of NA, PA and SWL were summed. This sum was divided by total number of items of SWL, PA and NA. The zero-order correlations among PGI, CSWB and presence of MIL, as well as the partial correlation of these variables controlling for age, were calculated using the factorial scores of the variables. The factorial scores of each construct were obtained through confirmatory factor analysis.

In this study, only the presence of MIL subscale was included in the mediation analysis and used as an indicator of the latent variable, MIL. As elaborated in the preceding paragraphs, the presence of MIL subscale is distinct from the search for MIL subscale, as it is associated with wellbeing and positive emotions. A mediation structural equation model (SEM) was implemented to evaluate a theoretical model in which levels of the presence of MIL mediated the relationship between PGI with CSWB. Age was inserted as a covariable into the SEM. The weighted least squares mean and variance adjusted (WLSMV), a recommended estimation method for non-normally distributed ordinal data, was used as estimation method (Muthén \& Muthén, 2010). To evaluate the mediation effects, the $95 \%$ confidence interval (CI) of the mediated effect was calculated via bootstrapping (1000 resampling).

The global model was assessed using the following model fit indices: the root mean square error of approximation (RMSEA), the comparative fit index (CFI) and the Tucker-Lewis index (TLI). According to these guidelines, the RMSEA value should be lower than .08 (with the $90 \%$ confidence interval not exceeding .10), and the CFI and TLI values should be greater than .90 (Brown, 2006).

\section{Results}

\section{Presence of MIL as a mediator of the relation between PGI and SWB}

Table 1 shows the descriptive data and zero-order correlations among the study variables. As expected, significant positive relationships were found among PGI, presence of MIL, and CSWB, which were at the moderate and large level (Cohen, 1988).

Among the socio-demographic variables, age was the only background variable significantly related to all of the latent variables of the study. Thus, it was included in the subsequent analyses and evaluated as a covariate in the SEM model.

Table 1. 
Descriptive Statistics and Zero-Order Correlations among Study Variables.

\begin{tabular}{lcccc}
\hline & $\boldsymbol{M}(\boldsymbol{S D})$ & $\mathbf{1}$ & $\mathbf{2}$ & $\mathbf{3}$ \\
\hline 1. PGI & $3.7(0.7)$ & - & $.45^{*}$ & $.38^{\star}$ \\
2. PMIL & $5.2(1.4)$ & $.46^{*}$ & - & $.49^{*}$ \\
3. CSWB & $2.1(0.6)$ & $.39^{*}$ & $.51^{*}$ & - \\
4. Age & 38.6 & $.14^{*}$ & $.30^{*}$ & $.17^{\star}$ \\
& $(16.1)$ & & & \\
\hline
\end{tabular}

Note. $\mathrm{N}=1,899{ }^{*} p \leq .001 . \mathrm{PGI}=$ Personal Growth Initiative; PMIL= Presence of Meaning in Life; CSWB = Composite of Subjective Well-Being.

The results of the SEM are shown in Figure 1. As can be seen, PGI is positively related to presence of MIL $(\beta=.50, p<.001)$ as well as to $\operatorname{CSWB}(\beta=.35, p<.001)$. The path from presence of MIL to CSWB is also positive $(\beta=.62, p<.001)$. With regard to age as a covariate, significant positive path coefficients from age to PGI $(\beta=.15, p<.001)$, and age to $\operatorname{MIL}(\beta=.25, p<.001)$ were observed. The fit indices of the model are satisfactory, as follows: $\left[\chi^{2}=5868.4^{*}, d f=8950, \chi^{2} / d f=0.65, \mathrm{CFI}=.94\right.$, TLI $=.94$, RMSEA $(90 \%$ CI $)=.05(.049-.050)]$, suggesting the plausibility of the model.

The results of mediation analysis reveal that presence of MIL partially mediated the relation between PGI and CSWB. The value of the standardized regression weight and the value of the standardized regression weight of the specific indirect effect of PGI on CSWB, via MIL, was $.310(p<.001,95 \%$ C.I. $=.258-.362)$. The presence of MIL accounted for almost half of the direct relationship between PGI and CSWB (47.18 \%).

\section{Discussion}

In this study, we examined the theoretical relationships among PGI, presence of MIL, and SWB, and tested a mediation model to reveal the underlying interactions among these psychological constructs. Considering their theoretical associations, we proposed PGI and presence of MIL as predictors of SWB and assessed whether presence of MIL serves as a mediator of the relationship between PGI and SWB.

As expected, the correlation analyses showed significant positive associations among the study variables. The results of SEM further provided support to our hypothesis that PGI was positively associated with presence of MIL, which in turn enhanced SWB measured through a composite score of satisfaction with life and positive and negative affect. Lastly, mediation analysis revealed that

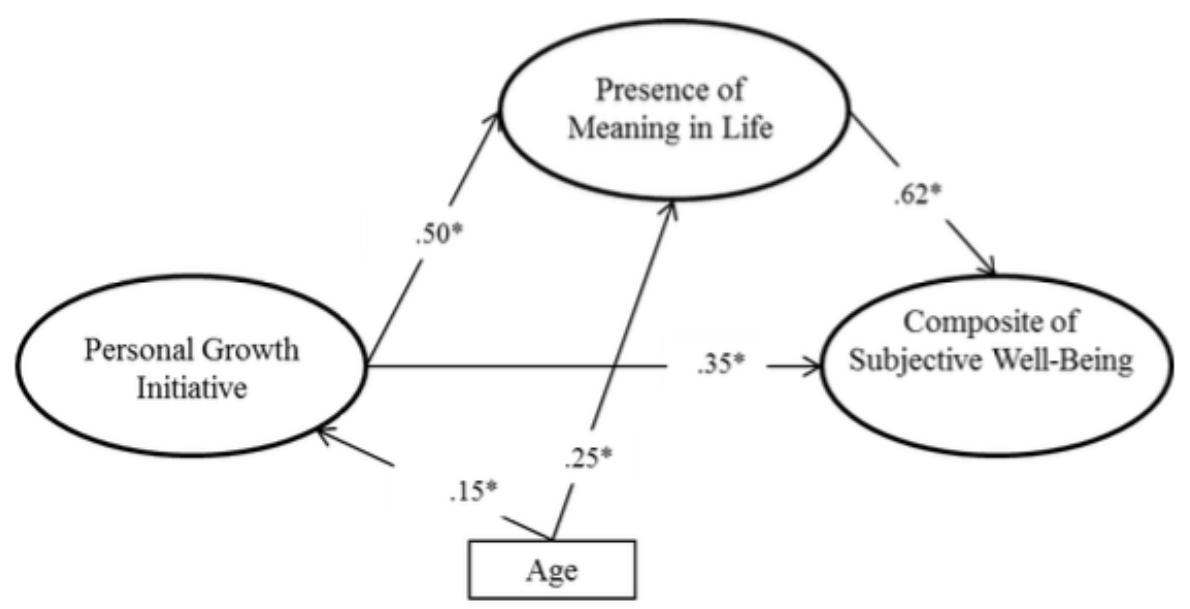

Figure 1. The structural model inter-relating PGI, presence of MIL, CSWB and Age. ${ }^{*} p<.001$. The items that compose each dimension are not shown to keep the chart simple and parsimonious. The effects between PGI and CSWB are the direct effects after controlling for the mediated effects.

of the total effect of PGI on CSWB was $.657(p<.001)$, presence of MIL partially mediated the relationship 
between PGI and SWB, suggesting that individuals who devote greater intentional effort to self-development and growth are those who experience greater presence of MIL, and as a result they will encounter greater levels of SWB.

Much of the empirical research has examined PGI and MIL in relation to the eudaimonic aspect of well-being, likely because the pursuit of personal growth and meaningfulness has been considered a fundamental component of eudaimonia concerned with the fulfillment of one's potential (Ryff, 1989; Steger et al., 2006, 2013). The focus of the present study is on SWB, an aspect of hedonistic well-being. According to the hedonistic view, well-being refers to pleasure or happiness characterized by the presence of positive affect and the absence of negative affect. A distinction between these two well-being perspectives is that the hedonistic tradition focuses on one's evaluation of one's emotions, whereas the eudaimonic tradition is concerned with one's evaluation of one's life functioning in general (Navascués, Calvo Medel, \& Bombin Martín, 2016; Ryan \& Deci, 2001). Although PGI and MIL have been viewed as eudaimonic in nature, their inverse relationship with negative emotions, and positive relationship with positive emotions, reported in several empirical research studies (e.g., Sood \& Gupta, 2014; Yalçın \& Malkoç, 2015; Yang \& Chang, 2014; Weigold, Porfeli, \& Weigold, 2013) provide evidence that PGI and MIL are congruent with the hedonistic tradition (Steger et al., 2013). In the present study, the significant positive relationships among PGI, presence of MIL, and SWB lend further support to their relevance within the hedonistic perspective and suggest that individuals who make a greater conscious effort toward their personal development tend to report higher levels of pleasure. The same applies to those who feel their lives are meaningful.

Why do high levels of PGI and presence of MIL contribute to an increase in SWB? An answer to this question might be framed in terms of the theories of PGI and MIL. According to the PGI theory, individuals with greater levels of intentional growth tend to perceive life events and experiences as opportunities, and they engage in growth-seeking behaviors to benefit from those opportunities (Robitschek et. al., 2012). For instance, when confronted with adversity, individuals with high PGI would be more likely to view adverse events or experiences as challenges that can spur self-development and growth, which leads them to maintain positive emotions and minimize negative ones (i.e., frustration, sadness, anger, etc.). Presence of MIL, on the other hand, may foster greater levels of SWB, because individuals who feel their lives are meaningful tend to adopt a positive outlook on the world, to effectively engage and cope with everyday life, and to successfully regulate their emotions (Steger et al., 2013), all of which is associated with greater happiness and life satisfaction. Therefore, the more meaning people encounter in their life, the greater happiness they experience.

The mediating effect of presence of MIL on the relationship between PGI and SWB is important to highlight, as presence of MIL accounted for $47.18 \%$ of the relationship, suggesting that it is an important route from PGI to SWB. This finding is not surprising, considering the fact that individuals with high levels of PGI have an overarching aim in life to grow and develop as humans, and they strive hard in the pursuit of this aim (Robitschek \& Kashubeck, 1999), which may in turn comprehend their life meaning. In other words, the conscious, goal-directed effort to grow as a person may bring a sense of meaning to an individual's life, as the striving toward purpose in life has also been linked to greater presence of MIL (Steger et al., 2006).

Moreover, the partial mediation effect of presence of MIL on PGI and SWB accounted for nearly half of the variance in the mediation model. This finding implied the existence of other factors in this relation. For example, individuals with high levels of PGI tend to search for support and resources in order to achieve personal growth (Robitschek et al., 2012). Initial evidence suggested a significant association between support resources and SWB (Chang et al., 2017; Luyckx \& Robitschek, 2014; Robitschek \& Keyes, 2009). Therefore, future studies should investigate the mediating role of other variables such as social support or relevant personal resources in the relationship between PGI and subjective well-being.

Finally, age was positively associated with presence of MIL and PGI, but not with SWB. The significant positive effect of age on PGI and MIL suggests that greater levels of PGI and presence of MIL are experienced later in life. Age differences have been reported with regard to PGI 
(e.g., Rapheal \& Paul, 2012; Luyckx \& Robitschek, 2014), indicating a positive association of higher levels of PGI and its dimensions with older age. The influence of age on MIL is also consistent with prior research, in which older participants were found to make more sense of their life experiences, despite dealing with the loss of loved ones, health problems, and physical decline (Battersby \& Phillips, 2016; Steger et al., 2009). The impact of age on PGI and MIL may be due to the fact that as people get older, they have better knowledge of what strategies can help them to grow and boost their self-improvement process, and they have more clarity about what brings meaning to their lives. Moreover, as people age, they are more likely to experience higher levels of professional and personal stability (e.g., financial stability, maturity), which in turn may have a positive impact on levels of MIL and PGI. On the other hand, no effect of age on SWB was reported, supporting the idea that SWB is stable over the lifespan (Park et al., 2010).

\section{Limitations and directions for future research}

The results of this study should be interpreted cautiously, as it has some limitations. First, an important limitation is related to the exclusive use of self-report instruments in assessing psychological constructs, which may produce bias by leading participants to respond in a positive way. Second, there are shortcomings related to the cross-sectional design of the study. Because of the nature of the study, no cause and effect relationships can be determined between the study variables. Thus, future research utilizing a longitudinal design may strength our knowledge with regard to the impacts of PGI and MIL on SWB over time. Another limitation is related to the sample for this study, which was composed of a single ethnic population - Brazilian participants. Although our sample was diverse, with a wide age range from 18 to 88 years, and included participants from different Brazilian states, it may not be representative of other populations. Further studies aiming to replicate and advance our findings using ethnically diverse samples are needed.

The results of this study should be interpreted cautiously, as it has some limitations. First, an important limitation is related to the exclusive use of self-report instru- ments in assessing psychological constructs, which may produce bias by leading participants to respond in a positive way. Second, there are shortcomings related to the cross-sectional design of the study. Because of the nature of the study, no cause and effect relationships can be determined between the study variables. Thus, future research utilizing a longitudinal design may strength our knowledge with regard to the impacts of PGI and MIL on SWB over time. Another limitation is related to the sample for this study, which was composed of a single ethnic population - Brazilian participants. Although our sample was diverse, with a wide age range from 18 to 88 years, and included participants from different Brazilian states, it may not be representative of other populations. Further studies aiming to replicate and advance our findings using ethnically diverse samples are needed.

\section{Conclusion}

Despite its limitations, the current study presents a significant contribution to the existing literature on SWB and its relation to the personal positive characteristics PGI and MIL. The findings show a mediating effect of presence of MIL on the relationship between PGI and SWB, assessed through a composite score of positive affect, negative affect, and life satisfaction. The results of this study should be taken into consideration when developing evidencebased interventions to promote the positive development of individuals.

\section{References}

Battersby, A. \& Phillips, L. (2016). In the End it all Makes sense: Meaning in Life at Either end of the Adult Lifespan. International Journal of Aging and Human Development, 83(2), 184-204. https://doi.org/ $10.1177 / 0091415016647731$

Brown, T. A. (2006). Confirmatory Factor Analysis for Applied Research. New York, NY: The Guilford Press. 
Busseri, M. A. \& Sadava, S. (2011). A Review of the Tripartite Structure of Subjective Well-Being: Implications for Conceptualization, Operationalization, Analysis, and Synthesis. Personality and Social Psychology Review, 15, 290-314. https://doi.org/10.1177/ 1088868310391271

Chang, E. C., Yang, H., Li, M., Duan, T., Dai, Y., Yang, J. Z., ... Chang, O. D. (2017). Personal Growth Initiative and Life Satisfaction in Chinese and American Students: Some Evidence for Using Resources in the East and Being Planful in the West. Journal of WellBeing Assessment, 1(1-3), 49-56. https://doi.org/ 10.1007/s41543-018-0004-2

Cohen, J. (1988). Statistical Power Analysis for the Behavioral Sciences (2nd ed.). Hillsdale, NJ: Erlbaum.

Cohen, K. \& Cairns, D. (2012). Is Searching for Meaning in Life Associated with Reduced Subjective Well-Being? Confirmation and Possible Moderators. Journal of Happiness Studies, 13(2), 313-331.

Damásio, B. F. \& Koller, S. H. (2015). Meaning in Life Questionnaire: Adaptation Process and Psychometric Properties of the Brazilian Version. Revista Latinoamericana de Psicología, 47(3), 185-195. https://doi.org/10.1016/j.rlp.2015.06.004

Diener, E., Emmons, R. A., Larsen, R. J., \& Griffin, S. (1985). The Satisfaction With Life Scale. Journal of Personality Assessment, 49(1), 71-75. https://doi.org/ 10.1207/s15327752jpa4901_13

Diener, E., Suh, E. M., Lucas, R. E., \& Smith, H. L. (1999). Subjective Well-being: Three Decades of Progress. Psychological Bulletin, 125(2), 276-302. https://doi.org/10.1037/0033-2909.125.2.276

Diener, E., Suh, E., \& Oishi, S. (1997). Recent Findings on Subjective Well-being. Indian Journal of Clinical Psychology, 24(1), 25-41. Retrieved from https://psycnet.apa.org/record/1997-43193-002

Doğan, T., Sapmaz, F., Tel, F. D., Sapmaz, S., \& Temizel, S. (2012). Meaning in Life and Subjective Well-being among Turkish University Students. Procedia-Social and Behavioral Sciences, 55, 612-617.

Freitas, C. P. P., Damásio, B. F., Kamei, H. H., Tobo, P. R., Koller, S. H. \& Robitschek, C. (2018). Personal Growth Initiative Scale - II: Adaptation and Psychometric Properties of the Brazilian version. Paidéia, 28, e2806. https://doi.org/10.1590/1982-4327e2806

Gable, S. L. \& Haidt, J. (2005). What (and why) is Positive Psychology? Review of General Psychology, 9, 103110. https://doi.org/10.1037/1089-2680.9.2.103

Galinha, I. C. \& Pais-Ribeiro, J. L. (2005). Contribuição para o estudo da versão portuguesa da Positive and Negative Affect Schedule (PANAS): II - Estudo Psicométrico [Contribution to the Study of the Portuguese Version of Positive and Negative Affect Schedule (PANAS): II - Psychometric Study]. Análise Psicológica, 2(XXIII), 219-227. Retrieved from http://www.scielo.mec.pt/scielo.php?script=sci_arttex t\&pid=S0870-82312005000200012\&lng=pt\&tlng=pt

Gouveia, V. V., Milfont, T. L., da Fonseca, P. N., Coelho, J. A. P. de M., \& Robitschek, C. (2009). Life Satisfaction in Brazil: Testing the Psychometric Properties of the Satisfaction With Life Scale (SWLS) in Five Brazilian Samples. Social Indicators Research, 90(2), 267-277. 1 https://doi.org/0.1007/s11205-008-9257-0

Hardin, E. E., Weigold, I. K., Robitschek, C., \& Nixon, A. E. (2007). Self-discrepancy and Distress: The Role of Personal Growth Initiative. Journal of Counseling Psychology, 54(1), 86-92. https://doi.org/10.1037/00220167.54.1.86

Hill, C. E., Bowers, G., Costello, A., England, J., HoustonLudlam, A., Knowlton, G., ... Thompson, B. J. (2013). What's It all about? A Qualitative Study of Undergraduate Students' Beliefs about Meaning of Life. Journal of Humanistic Psychology, 53, 386-414. https://doi.org/10.1177/ 0022167813477733

Hill, C. E., Kline, K., Bauvan, V., Brent, T., Breslin, C., Calderon, M., ... Knox, S. (2015). What's it all about? A Qualitative Study of Meaning in Life for Counseling 
Psychology Doctoral Students. Counselling Psychology Quarterly, 28(1), 1-26. https://doi.org/ $10.1080 / 09515070.2014 .965660$

Instituto Brasileiro de Geografia e Estatística. (2010). Censo Demográfico 2010: Características da população e dos domicílios - Resultados do Universo [Census 2010: Population Characteristics and Household Universe Results]. Rio de Janeiro, RJ: IBGE.

Ivtzan, I., Chan, C. P. L., Gardner, H. E., \& Prashar, K. (2011). Linking Religion and Spirituality with Psychological Wellbeing: Examining Self-Actualisation, Meaning in Life, and Personal Growth Initiative. Journal of Religion and Health, 51, 13-30. https://doi.org/ 10.1007/s10943-011-9540-2

Kashdan, T. B. \& Steger, M. F. (2007). Curiosity and Pathways to Well-Being and Meaning in Life: Traits, States, and Everyday Behaviors. Motivation and Emotion, 31, 159-173. https://doi.org/10.1007/s11031007-9068-7

Linley, P. A., Maltby, J., Wood, A. M., Osborne, G., \& Hurling, R. (2009). Measuring Happiness: The higher order Factor Structure of Subjective and Psychological Well-Being Measures. Personality and Individual Differences, 47(8), 878-884. https://doi.org/10.1016/ j.paid.2009.07.010

Luyckx, K. \& Robitschek, C. (2014). Personal Growth Initiative and Identity Formation in Adolescence Through young Adulthood: Mediating Processes on the Pathway to Well-Being. Journal of Adolescence, 37(7), 973-981. https://doi.org/0.1016/j.adolescence.2024.07 .009

Meyers, M. C., van Woerkom, M., de Reuver, R. S. M., Bakk, Z., \& Oberski, D. L. (2015). Enhancing Psychological Capital and Personal Growth Initiative: Working on Strengths or Deficiencies. Journal of Counseling Psychology, 62(1), 50-62. https://doi.org/ $10.1037 /$ cou0000050
Muthén, L. K. \& Muthén, B. O. (2010). Mplus: Statistical analysis with Latent Variables. User's guide. Los Angeles, CA: Muthén \& Muthén.

Navascués, A., Calvo Medel, D., \& Bombin Martín, A. (2016). Efectos del bienestar subjetivo y psicológico en los resultados terapéuticos de un hospital de día [Effects of Subjective and Psychological Well-Being on the Therapeutic Outcomes at a Day Hospital]. Acción Psicológica, 13(2), 143-156. https://doi.org/ 10.5944/ap.13.2.15818

Park, N., Park, M., \& Peterson, C. (2010). When is the Search for Meaning Related to Life Satisfaction? Applied Psychology: Health and Well-Being, 2(1), 113. https://doi.org/10.1111/j.1758-0854.2009.01024.x

Prager, E. (1996). Exploring Personal Meaning in an AgeDifferentiated Australian Sample: Another Look at the Sources of Meaning Profile (SOMP). Journal of Aging Studies, 10(2), 117-136. https://doi.org/10.1016/ S0890-4065(96)90009-2

Rapheal, J. \& Paul, V. K. (2012). Self-Actualization and Personal Growth Initiative among the Teachers of Adolescents. Scopus, 2(2), 61-65.

Robitschek, C. (1998). Personal Growth Initiative: The Construct and its Measure. Measurement and Evaluation in Counseling and Development, 30(4), 183-198. Retrieved from https://psycnet.apa.org/record/199800149-002

Robitschek, C. \& Kashubeck, S. (1999). A Structural Model of Parental Alcoholism, Family Functioning, and Psychological Health: The Mediating Effects of Hardiness and Personal Growth Orientation. Journal of Counseling Psychology, 46, 159-172. Retrieved from https://psycnet.apa.org/record/1999-10585-002

Robitschek, C. \& Keyes, C. L. M. (2009). Keyes’ Model of Mental Health with Personal Growth Initiative as a Parsimonious Predictor. Journal of Counseling Psychology, 56, 321-329. https://doi.org/10.1037/ a0013954 
Robitschek, C., Ashton, M. W., Spering, C. C., Geiger, N., Byers, D., Schotts, G. C., \& Thoen, M. A. (2012). Development and Psychometric Evaluation of the Personal Growth Initiative Scale-II. Journal of Counseling Psychology, 59(2), 274-287. https://doi.org/ 10.1037/a0027310

Ryan, R. M. \& Deci, E. L. (2001). On Happiness and Human Potentials: A Review of Research on Hedonic and Eudaimonic Well-being. Annual Review of Psychology, 52, 141-166. https://doi.org/10.1146/annurev. psych.52.1.141

Ryff, C. D. (1989). Happiness is Everything, or is it? Explorations on the Meaning of Psychological wellbeing. Journal of Personality and Social Psychology, 57, 1069-1081 https://doi.org/10.1037/00223514.57.6.1069

Seligman, M. E. \& Csikszentmihalyi, M. (2000). Positive Psychology: An Introduction. American Psychologist, 55(1), 5-14. https://doi.org/10.1037/0003066X.55.1.5

Steger, M. F., Frazier, P., Oishi, S., \& Kaler, M. (2006). The Meaning in Life Questionnaire: Assessing the Presence of and Search for Meaning in Life. Journal of Counseling Psychology, 53(1), 80-93. https://doi.org/ 10.1037/0022-0167.53.1.80

Steger, M. F., Oishi, S., \& Kashdan, T. B. (2009). Meaning in Life across the Life Span: Levels and Correlates of Meaning in Life from Emerging Adulthood to Older Adulthood. The Journal of Positive Psychology, 4(1), 43-52. https://doi.org/10.1080/ 17439760802303127

Steger, M. F., Oishi, S., \& Kesebir, S. (2011). Is a Life without Meaning Satisfying? The Moderating Role of the Search for Meaning in Satisfaction with Life Judgments. The Journal of Positive Psychology, 6(3), 173180. https://doi.org/10.1080/17439760. 2011.569171

Steger, M. F., Shin, J. Y., Shim, Y., \& Fitch-Martin, A. (2013). Is Meaning in Life a Flagship Indicator of Well-being? In A. S. Waterman (Ed.), The Best within us: Positive Psychology Perspectives on Eudaimonia. (pp. 159-182). Washington: American Psychological Association.

Sood, S. \& Gupta, R. (2014). Subjective Happiness as Mediator between Personal Growth Initiative and Life Satisfaction in Adolescents. International Journal of Psychological Studies, 6(4), 89-94. https://doi.org/ 10.5539/ijps.v6n4p89

Taubman-Ben-Ari, O., Ben Shlomo, S., \& Findler, L. (2012). Personal Growth and Meaning in Life among First-Time Mothers and Grandmothers. Journal of Happiness Studies, 13, 801-820. https://doi.org/ 10.1007/s10902-011-9291-5

Taubman-Ben-Ari, O. \& Weintroub, A. (2008). Meaning in Life and Personal Growth among Pediatric Physicians and Nurses'. Death Studies, 32, 7, 621-645. https://doi.org/0.1080/07481180802215627.

Watson, D., Clark, L. A., \& Tellegen, A. (1988). Development and Validation of Brief Measures of Positive and Negative Affect: The PANAS Scales. Journal of Personality and Social Psychology, 54(6), 1063-1070. https://doi.org/10.1037/0022-3514.54.6.1063

Weigold, I. K., Porfeli, E. J., \& Weigold, A. (2013). Examining Tenets of Personal Growth Initiative Using the Personal Growth Initiative Scale-II. Psychological Assessment, 25(4), 1396-1403. https://doi.org/ 10.1037/a0034104

Yalçın, İ. \& Malkoç, A. (2015). The Relationship Between Meaning in Life and Subjective Well-Being: Forgiveness and Hope as Mediators. Journal of Happiness Studies, 16(4), 915-929. https://doi.org/ 10.1007/ s10902-014-9540-5

Yang, H. \& Chang, E. C. (2014). Examining the Structure, Reliability, and Validity of the Chinese Personal Growth Initiative Scale-II: Evidence for the Importance of Intentional Self-Change among Chinese. Journal of Personality Assessment, 96(5), 1-8. https://doi.org/10.1080/00223891.2014.886256 
